\title{
Diet and the Gut
}

\author{
Kamran B. Lankarani ${ }^{1 *}$
}

1. Health Policy Research Center, Shiraz University of Medical Sciences, Shiraz, Islamic Republic of Iran

Please cite this paper as:

Lankarani K.B Diet and the Gut. Middle East J Dig Dis 2016:8:161-165. DOI :10.15171/ mejdd.2016.28

$29^{\text {th }}$ of May has been convened as the World Digestive Health Day (WDHD) by the World Gastroenterology Organization (WGO) since 2005. This event is an opportunity to raise public awareness on topics related to gastrointestinal tract diseases and health. The theme of 2016 is "diet and the gut".

The traditional approach to diet in gastroenterology practice is to advise patients to avoid certain foods to control their symptoms and /or diseases. The classic example of causative role of food in a disease is celiac disease for which the main management is gluten free diet (GFD). ${ }^{1}$ In patients with lactase or fructase deficiency, ingestion of lactose or fructose would lead to flatulence. Many such patients have learned to avoid certain foods. Food allergy is yet another example of food as a cause of disease. Examples include milk and wheat allergy. The latter should not be confused with celiac disease because of different pathogenesis and clinical presentations. ${ }^{2}$

\section{Gastroesophageal reflux disease (GERD)}

More commonly gastroenterologists as well as other medical professionals advise patients to avoid certain foods to control their symptoms. Coffee, tea, acidic juices, carbonated beverage, onion, fatty and spicy foods among others are well known examples of foods exacerbating pyrosis and heartburn in GERD ${ }^{3,4}$ Eating and sleep pattern may also have effect on symptom severity in GERD. ${ }^{5}$

\section{Irritable bowel syndrome (IBS)}

Patients with irritable bowel syndrome (IBS) depending on their dominant symptoms find some foods deteriorating their symptoms and some other foods improving the symptoms. ${ }^{6}$ Flatulence and pain are exacerbated by ingestion of non-digestible foods such as legumes, some grains, certain vegetables, and in those with either lactase or fructase deficiency with foods containing these sugars as discussed above. Constipation on the other hand is relieved by ingestion of fibers, which are abundant in vegetables and fruits.

There are reports of certain food intolerance in up to $40 \%$ of patients with IBS. They vary from milk and other dairy products, carbonated beverage, fat, and certain vegetables to wheat. ${ }^{7}$ Fermentable oligo-, di- and mono-saccharides polyols (FODMAPs) have become focus of interest for their possible role in symptom exacerbation both in IBS and inflammatory bowel disease (IBD). Ingestion of foods containing FODMAPs leads to excessive delivery 
of these small molecules, which are highly fermentable but poorly absorbable short chain carbohydrates and polyols, to the colon and probably distal small bowel that may affect the microbiota. ${ }^{8}$ Diets low in FODMAPs may improve the symptoms of patients with IBS especially in those suffering from fructose deficiency. ${ }^{9}$

Up to $10 \%$ of general population in some countries report better feeling when they consume GFD. ${ }^{10}$ Although some of these patients may have latent or atypical celiac disease, most of them cannot be categorized in this entity. The term non-celiac gluten sensitivity (NCGS) has been proposed for such patients whose symptoms might be dyspepsia, IBS like, neuropsychiatric, or fibromyalgia. ${ }^{11,12}$ Several researchers have shown that use of GFD may lead to symptoms improvement in up to one third of patients with IBS. ${ }^{10,13}$

It has been suggested that other gluten-based components including fermentable oligo, di, and mono-saccharides and polyols, amylase trypsin inhibitors, and wheat germ agglutinins may contribute to these symptoms. The term non-celiac wheat sensitivity has been proposed instead of NCGS to indicate possible importance of such components. ${ }^{14}$ There is a growing international market for GFD. ${ }^{15}$ It is estimated that the market in the United States would reach 6.6 billion US dollars in $2017 .{ }^{10}$ Part of this is probably due to an induced demand orchestrated by some food industries.

\section{Inflammatory bowel disease (IBD)}

As there is an increasing trend in the incidence of IBD worldwide specially in developing countries, there have been concerns about the role of dietary habits in the pathogenesis of IBD. ${ }^{16}$ There are reports of increased risk of IBD, both ulcerative colitis and Crohn's disease (CD), with higher intake of sugar or sugar-containing foods/soft drinks and lower intake of fruits and/or vegetables but such reports were not consistent in all studies. ${ }^{17,18}$ Grain-derived products were reported to have a protective role in the onset of $\mathrm{CD}$ but this was not confirmed in all studies. ${ }^{17,18}$ The results on risk of IBD and higher intake of unsaturated fatty acids (UFA) and the level of protein and energy intake were also inconsistent in different reports. ${ }^{17}$

Diet as a preventive measure for gastrointestinal diseases

Yet another approach, which is mostly looked after by patients, is to receive advice on what to eat to avoid the disease. Patients want not only the knowledge on what should be avoided, but also on what would be beneficial for them. As mentioned before our current practice is mostly based on avoidance rather than promotion of what should be eaten.

One of the best recent findings is the use of the so called Mediterranean diet as a protective measure for many diseases including GERD. This diet include frequent consumption of composite/traditional dishes, fresh fruit and vegetables, olive oil, and fish rather than westernized diet characterized by frequent consumption of red meat, fried food, sweets, carbonated beverage, and junk/ fast food.

Better understanding of the role of microbiota in health and disease and the way they are developed in individuals, have shifted the interest of researchers towards dietary interventions that could change the microbiota to a healthier pattern. ${ }^{19}$ The concept of prebiotics was introduced to describe those food components or ingredients that enrich for favorable organisms in the gastrointestinal tract (GIT). ${ }^{20}$ These dietary interventions could be used to change the colonic microbiota, however the change is usually transient. ${ }^{21}$ Concomitant use of prebiotics and probiotics, which has been called synbiotics have been used to produce more stable changes in colonic microbiota. ${ }^{22}$ Natural prebiotics include fibers that are found in whole grains, fruits, root and other vegetables, and legumes among others. These fibers promote the growth of beneficial organisms. ${ }^{19}$ This process occurs mainly through fermentation of these non-digestible carbohydrates to butyrate and other short chain fatty acids. Their production would lower intraluminal $\mathrm{pH}$ in colon, which in turn stimulate mucin production by large bowel epithelium and immunomodulatory cytokines by immune system. ${ }^{23}$ In real practice use these fibers are not clinically effective in all occasions. The reason could be the physiological differences in patients own microbiota to consume such prebiotics. ${ }^{19}$

Traditional Iranian medicine has considered a proactive rule of diet in maintaining the health. ${ }^{24,25}$ Prunes (Prunus domestica L.), mastic (Pistacia lentiscus L.), saffron (Crocus sativus L.), aloe (Aloe barbadensis Miller), ginger (Zingiber officinale Rosc.), lemon (Citrus limon L.) and black mustard (Brassica nigra L.) have 
had various beneficial effect in maintaining the health of GIT. $^{24,26,27}$

\section{Diet and prevention of gastrointestinal cancers}

In non-smokers/non-alcoholic drinkers, diet and physical activity are the major modifiable risk factors for prevention of cancer. Based on the national data from Iran the contributory risk of diet to burden of esophageal, gastric, and colon cancers were estimated $22.1 \%$ (C.I 5.56-42.76), 46.84\% (C.I 27.79-66.25), and 44.63\% (C.I $35.45-53.2$ ), respectively on year $2013 .^{28}$

Obesity increases the risk of almost all gastrointestinal cancers. ${ }^{29}$ In this regards any dietary intervention that helps to reduce weight in obese patients could be considered as a cancer preventive measure. ${ }^{30}$

Researchers have also tried to investigate in depth relation of diet and cancer. The protective effect of fibers and unrefined cereals as well as detrimental influence of red meat and fat on developing colorectal cancer have been shown in several studies. ${ }^{31}$ These dietary habits may act by alteration of colonic microbiota. The so called westernized dietary habits characterized by high meat and fat consumption and low fiber intake might be one of the reasons for increasing the incidence of colorectal cancers in Iran and other developing countries..$^{31,32}$ Low serum copper and zinc level were reported in Iranian patients with colorectal cancer but the clinical significance is not well defined. ${ }^{33}$ Low selenium and zinc levels were also proposed as risk factors for squamous cell carcinoma of esophagus (SCC) but the findings are not consistent in all studies to conclude for a causative role. ${ }^{34,35}$ Cooking methods exposing patients to polycyclic aromatic hydrocarbons (PAHs) increased the risk of SCC of esophagus. ${ }^{35,36}$ Consumption of hot tea whether it was black or green have been shown in different studies to increase the risk of SCC of esophagus. ${ }^{37,38}$ Dietary risk factors for esophageal adenocarcinoma include obesity, and low fruit and vegetable intake. ${ }^{39}$

Salted or salty foods, fried and processed meats and foods high in N-nitroso compounds increase the risk of gastric cancer while consumption of fruits, and unprocessed vegetables had protective effect. ${ }^{40,41}$ A recent study from Iran revealed that higher red meat consumption increased the risk of gastric cancer, while high white meat consumption might have a protective effect. ${ }^{42}$ Same findings have been reported for pancreatic cancer. ${ }^{43}$

Overall one can conclude that reducing BMI to below 25 , increasing the intake of fruits, vegetable, and fresh fish along with avoidance of high intake of red meat, and slated/salty and processed foods can be considered protective for gastrointestinal cancers.

\section{CONCLUSION}

Diet could be used as a health promoting intervention in GIT diseases and health. There is still a huge need for well-designed studies to reach scientific conclusions in this regard.

\section{CONFLICT OF INTEREST}

The author declares no conflict of interest related to this work.

\section{REFERENCES}

1. Lundin KE, Qiao SW, Snir O, Sollid LM. Coeliac disease - from genetic and immunological studies to clinical applications. Scand J Gastroenterol 2015;50:708-17. doi: 10.3109/00365521.2015.1030766.

2. $\quad$ Savage J, Johns CB. Food Allergy. Immunol Allergy Clin North Am 2015;35:45-59. doi: 10.1016/j.iac.2014.09.004.

3. Meining A, Classen M. The role of diet and lifestyle measures in the pathogenesis and treatment of gastroesophageal reflux disease. Am J Gastroenterol 2000;95:2692-7. doi:10.1111/j.1572-0241.2000.03175.x

4. Mone I, Kraja B, Bregu A, Duraj V, Sadiku E, Hyska J, et al. Adherence to a predominantly Mediterranean diet decreases the risk of gastroesophageal reflux disease: a cross-sectional study in a South Eastern European population. Dis Esophagus 2015. doi: 10.1111/dote.12384.

5. Esmaillzadeh A, Keshteli AH, Feizi A, Zaribaf F, FeinleBisset C, Adibi P. Patterns of diet-related practices and prevalence of gastro-esophageal reflux disease. Neurogastroenterol Motil 2013;25:831-e638. doi: 10.1111/nmo. 12192.

6. Hashemian M, Nasrabadi FM, Hekmatdoost A, Poustchi H, Malekzadeh R. Medical Nutrition Therapy in Irritable Bowel Syndrome. Govaresh 2014;19:155-66.

7. Heizer WD, Southern S, McGovern S. The role of diet in symptoms of irritable bowel syndrome in adults: a narrative review. $J$ Am Diet Assoc 2009;109:1204-14. doi: 10.1016/j.jada.2009.04.012.

8. Chumpitazi BP, Cope JL, Hollister EB, Tsai CM, McMeans AR, Luna RA, et al. Randomised clinical trial: gut microbiome biomarkers are associated with clinical response to a low FODMAP diet in children with the irritable 
bowel syndrome. Aliment Pharmacol Ther 2015;42:41827. doi: 10.1111/apt.13286.

9. de Roest RH, Dobbs BR, Chapman BA, Batman B, O'Brien LA, Leeper JA, et al. The low FODMAP diet improves gastrointestinal symptoms in patients with irritable bowel syndrome: a prospective study. Int $J$ Clin Pract 2013;67:895-903. doi: 10.1111/ijcp.12128.

10. Aziz I, Dwivedi K, Sanders DS. From coeliac disease to noncoeliac gluten sensitivity; should everyone be gluten free? Curr Opin Gastroenterol 2016;32:120-7. doi: 10.1097/MOG.0000000000000248.

11. Aziz I, Hadjivassiliou M, Sanders DS. The spectrum of noncoeliac gluten sensitivity. Nat Rev Gastroenterol Hepatol 2015;12:516-26. doi: 10.1038/nrgastro.2015.107.

12. Branchi F, Aziz I, Conte D, Sanders DS. Noncoeliac gluten sensitivity: a diagnostic dilemma. Curr Opin Clin Nutr Metab Care 2015;18:508-14. doi: 10.1097/ MCO.0000000000000207.

13. Shahbazkhani B, Sadeghi A, Malekzadeh R, Khatavi F, Etemadi M, Kalantri E, et al. Non-Celiac Gluten Sensitivity Has Narrowed the Spectrum of Irritable Bowel Syndrome: A Double-Blind Randomized Placebo-Controlled Trial. Nutrients 2015;7:4542-54. doi: 10.3390/nu 7064542 .

14. Mansueto P, D'Alcamo A, Seidita A, Carroccio A. Food allergy in irritable bowel syndrome: The case of non-celiac wheat sensitivity. World J Gastroenterol 2015;21:7089109. doi: 10.3748/wjg.v21.i23.7089.

15. Golley S, Corsini N, Topping D, Morell M, Mohr P. Motivations for avoiding wheat consumption in Australia: results from a population survey. Public Health Nutr 2015;18:490-9. doi: 10.1017/S1368980014000652.

16. Taghavi SAR, Safarpour S, Hosseini SV, Noroozi H, Safarpour M, Rahimikazerooni S. Epidemiology of Inflammatory Bowel Diseases (IBD) in Iran: A Review of 740 Patients in Fars Province, Southern Iran. Ann Colorectal Res 2013;1:17-22.

17. Spooren CE, Pierik MJ, Zeegers MP, Feskens EJ, Masclee AA, Jonkers DM. Review article: the association of diet with onset and relapse in patients with inflammatory bowel disease. Aliment Pharmacol Ther 2013;38:1172-87. doi: 10.1111/apt.12501.

18. Racine A, Carbonnel F, Chan SS, Hart AR, Bueno-deMesquita HB, Oldenburg B, et al. Dietary Patterns and Risk of Inflammatory Bowel Disease in Europe: Results from the EPIC Study. Inflamm Bowel Dis 2016;22:345-54. doi: 10.1097/MIB.0000000000000638.

19. Krumbeck JA, Maldonado-Gomez MX, Ramer-Tait AE, Hutkins RW. Prebiotics and synbiotics: dietary strategies for improving gut health. Curr Opin Gastroenterol 2016;32:110-9. doi: 10.1097/MOG.0000000000000249.

20. Gibson GR, Roberfroid MB. Dietary modulation of the human colonic microbiota: introducing the concept of prebiotics. J Nutr 1995;125:1401-12.
21. Walker AW, Lawley TD. Therapeutic modulation of intestinal dysbiosis. Pharmacol Res 2013;69:75-86. doi: 10.1016/j.phrs.2012.09.008.

22. Krumbeck JA, Maldonado-Gomez MX, Martinez I, Frese SA, Burkey TE, Rasineni K, et al. In vivo selection to identify bacterial strains with enhanced ecological performance in synbiotic applications. Appl Environ Microbiol 2015;81:2455-65. doi: 10.1128/AEM.03903-14

23. Preidis GA, Versalovic J. Targeting the Human Microbiome With Antibiotics, Probiotics, and Prebiotics: Gastroenterology Enters the Metagenomics Era. Gastroenterology 2009;136:2015-31. doi : /10.1053/j.gastro.2009. 01.072

24. Pasalar M, Zarshenas MM, Lankarani KB. Good Digestion is a Key Element for Healthy Hearts: An Appealing Concept from Avicennaâ€т s Viewpoint. Medical Hypothesis, Discov Innovation Interdisciplinary Sciences Journal. 2014;1.

25. Mosaffa Jahromi M, Pasalar M, Afsharypuor S, Choopani R, Mosaddegh M, Kamalinejad M, et al. Preventive Care for Gastrointestinal Disorders; Role of Herbal Medicines in Traditional Persian Medicine. Jundishapur J Nat Pharm Prod. 2015;10:e21029.

26. Pasalar M, Lankarani KB. Letter: prunes for the treatment of constipation. Aliment Pharmacol Ther 2015;41:234. doi: 10.1111/apt.13018.

27. Pasalar M LK, Mehrabani D, Tolide-ie HR, Naseri M. The effect of Descurainia sophia L. and Prunus domestica L. in prevention of constipation among Iranian Hajj Pilgrims, Saudi Arabia. Res J Pharm Biol Chem Sci 2013;4:195-204

28. evaluation Ifhma. Global burden of disease 2016 [cited 2016 1/4/2016]. Available from: http://vizhub.healthdata. org/gbd-compare/.

29. Kant P, Hull MA. Excess body weight and obesity--the link with gastrointestinal and hepatobiliary cancer. Nat Rev Gastroenterol Hepatol 2011;8:224-38. doi: 10.1038/ nrgastro.2011.23.

30. Berger NA. Obesity-associated gastrointestinal tract cancer: from beginning to end. Cancer 2014;120:935-9. doi: $10.1002 /$ cncr.28534.

31. Bishehsari F, Mahdavinia M, Vacca M, Malekzadeh R, Mariani-Costantini R. Epidemiological transition of colorectal cancer in developing countries: environmental factors, molecular pathways, and opportunities for prevention. World $J$ Gastroenterol 2014;20:6055-72. doi: 10.3748/wjg.v20.i20.6055.

32. Rezaianzadeh A, Safarpour AR, Marzban M, Mohaghegh A. A Systematic Review Over the Incidence of Colorectal Cancer in Iran. Ann Colorectal Res 2015;3:e25724. doi : 10.17795/acr-25724

33. Khoshdel Z, Naghibalhossaini F, Abdollahi K, Shojaei S, Moradi M, Malekzadeh M. Serum Copper and Zinc Levels Among Iranian Colorectal Cancer Patients. Biol Trace Elem Res 2016;170:294-9. doi: 10.1007/s12011015-0483-4. 
34. Hashemian M, Hekmatdoost A, Poustchi H, Mohammadi Nasrabadi F, Abnet CC, Malekzadeh R. Systematic review of zinc biomarkers and esophageal cancer risk. Middle East J Dig Dis 2014;6:177-85.

35. Kamangar F, Malekzadeh R, Dawsey SM, Saidi F. Esophageal cancer in Northeastern Iran: a review. Arch Iran Med 2007;10:70-82.

36. Islami F, Boffetta P, van Schooten FJ, Strickland P, Phillips DH, Pourshams A, et al. Exposure to Polycyclic Aromatic Hydrocarbons Among Never Smokers in Golestan Province, Iran, an Area of High Incidence of Esophageal Cancer - a Cross-Sectional Study with Repeated Measurement of Urinary 1-OHPG in Two Seasons. Front Oncol 2012;2:14. doi: 10.3389/fonc.2012.00014.

37. Wu M, Liu AM, Kampman E, Zhang ZF, Van't Veer P, Wu DL, et al. Green tea drinking, high tea temperature and esophageal cancer in high- and low-risk areas of Jiangsu Province, China: a population-based case-control study. Int J Cancer 2009;124:1907-13. doi: 10.1002/ijc.24142.

38. Islami F, Pourshams A, Nasrollahzadeh D, Kamangar F, Fahimi S, Shakeri R, et al. Tea drinking habits and oesophageal cancer in a high risk area in northern Iran: population based case-control study. BMJ 2009;338:b929. doi: 10.1136/bmj.b929.

39. Pohl H, Wrobel K, Bojarski C, Voderholzer W, Sonnenberg A, Rösch T, et al. Risk factors in the development of esophageal adenocarcinoma. Am J Gastroenterol 2013;108:200-7. doi: 10.1038/ajg.2012.387.

40. Tsugane S, Sasazuki S. Diet and the risk of gastric cancer: review of epidemiological evidence. Gastric Cancer 2007;10:75-83.

41. Peleteiro B, Lopes C, Figueiredo C, Lunet N. Salt intake and gastric cancer risk according to Helicobacter pylori infection, smoking, tumour site and histological type. $B r J$ Cancer 2011;104:198-207. doi: 10.1038/sj.bjc.6605993.

42. Zamani N, Hajifaraji M, Fazel-tabar Malekshah A, Keshtkar AA, Esmaillzadeh A, Malekzadeh R. A case-control study of the relationship between gastric cancer and meat consumption in Iran. Arch Iran Med 2013;16:324-9. doi: 013166/AIM.004.

43. Ghorbani Z, Hekmatdoost A, Zinab HE, Farrokhzad S, Rahimi R, Malekzadeh R, et al. Dietary food groups intake and cooking methods associations with pancreatic cancer: a case-control study. Indian J Gastroenterol 2015;34:225-32. doi: 10.1007/s12664-015-0573-4. 